\title{
Synthesis and Mechanical Properties of New Cu-Based Cu-Zr-Al Glassy Alloys with Critical Diameters up to Centimeter Order
}

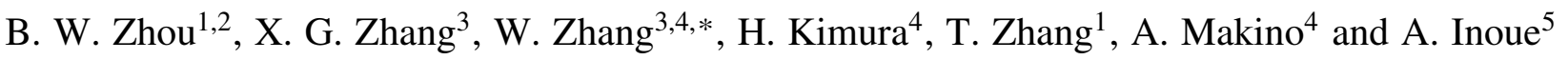 \\ ${ }^{1}$ Graduate school, School of Materials Science and Engineering, Dalian University of Technology, Dalian, 116024, P. R. China \\ ${ }^{2}$ Graduate School, Tohoku University, Sendai 980-8577, Japan \\ ${ }^{3}$ School of Materials Science and Engineering, Dalian University of Technology, Dalian, 116024, P. R. China \\ ${ }^{4}$ IMR, Tohoku University, Sendai 980-8577, Japan \\ ${ }^{5}$ WPI, Tohoku University, Sendai 980-8577, Japan
}

A new $\mathrm{Cu}$-based $\mathrm{Cu}-\mathrm{Zr}$-Al glassy alloy has been found to exhibit very high glass-forming ability, wide supercooled liquid region and high fracture strength. The addition of $\mathrm{Al}$ to a binary eutectic $\mathrm{Cu}_{55} \mathrm{Zr}_{45}$ alloy significantly increases the stabilization of supercooled liquid as well as glass-forming ability in $\mathrm{Cu}_{55-x} \mathrm{Zr}_{45} \mathrm{Al}_{x}$ ( $x=0$ to 10) alloy series. The largest supercooled liquid region of $80 \mathrm{~K}$, reduced glass transition temperature of 0.60 and $\gamma$ value of 0.417 are simultaneously obtained for a ternary eutectic $\mathrm{Cu}_{47} \mathrm{Zr}_{45} \mathrm{Al}_{8}$ alloy, which can fabricate fully glassy sample with critical diameters up to $15 \mathrm{~mm}$ by copper mold casting. The bulk glassy alloy also exhibits high compressive fracture strength of over $1900 \mathrm{MPa}$ and the high Young's modulus above $100 \mathrm{GPa}$. [doi:10.2320/matertrans.MBW200928]

(Received December 1, 2009; Accepted February 2, 2010; Published March 17, 2010)

Keywords: glassy alloy, copper-based alloy, thermal stability, glass-forming ability, mechanical property

\section{Introduction}

Bulk glassy alloys (BGAs) have been expected to be used in wide application fields, because they exhibit many unique properties such as high strength, large elastic strain limit, high hardness, good soft magnetic properties, excellent corrosion resistance and viscous flow workability in the supercooled liquid region. ${ }^{1,2)}$ However, for practical applications as the structural materials, BGAs are requested to simultaneously possess high glass-forming ability (GFA), high strength, good toughness, high corrosion resistance and low cost. The BGAs with high strength and good toughness can be obtained for the alloys consisting only of metallic elements, such as $\mathrm{Zr}-{ }^{2,3)} \mathrm{Ti}_{-},{ }^{4)} \mathrm{Ni}_{-},{ }^{5-7)} \mathrm{Cu}^{-\mathrm{Ti}^{-}}{ }^{8}$ and $\mathrm{Cu}-$ based $^{9-11)}$ systems, and the Zr-based alloys have higher GFA more than other alloys. Recently, much attention has been paid to $\mathrm{Cu}$-based BGAs because they not only have lower cost, but also exhibit higher strength and higher thermal stability against crystallization as compared to $\mathrm{Zr}$-based BGAs. ${ }^{12-14)}$

It is important to develop binary or ternary glassy alloys with high GFA because they are base of the multi-component BGAs, and the GFA can be improved by alloying more components into the base alloys. Actually, the Cu-based BGAs can be prepared in the binary $\mathrm{Cu}-\mathrm{Zr}$ alloys by copper mold casting, ${ }^{15-17)}$ and the GFA is effectively enhanced by addition of a small amount of third elements, resulting in development of the ternary $\mathrm{Cu}$-based BGAs with high GFA in $\mathrm{Cu}-\mathrm{Zr}-\mathrm{Ti}$ and $\mathrm{Cu}-\mathrm{Zr}-\mathrm{Al}$, and $\mathrm{Cu}-\mathrm{Zr}-\mathrm{Ag}$ systems. ${ }^{9-11)}$ However, their critical diameters $\left(d_{\mathrm{c}}\right)$ for glass formation were below $6 \mathrm{~mm}$, and the $d_{\mathrm{c}}$ are only 3-4 mm for $\mathrm{Cu}-\mathrm{Zr}-\mathrm{Ti}$ and $\mathrm{Cu}-\mathrm{Zr}-\mathrm{Al}$ alloys, which have lower cost.9,10)

It has been reported that $\mathrm{Zr}$-rich $\mathrm{Zr}-\mathrm{Cu}-\mathrm{Al}$ alloys exhibit high reduced glass transition temperature $\left(T_{\mathrm{rg}}=T_{\mathrm{g}} / T_{1}, T_{\mathrm{g}}\right.$ : glass transition temperature; $T_{1}$ : liquidus temperature) ${ }^{18)}$ and

*Corresponding author, E-mail: wzhang@imr.tohoku.ac.jp $\gamma$ value $\left(\gamma=T_{\mathrm{x}} /\left(T_{\mathrm{g}}+T_{1}\right), T_{\mathrm{x}} \text { : crystallization temperature }\right)^{19)}$ as well as a large supercooled liquid region $\left(\Delta T_{x}=\right.$ $\left.T_{\mathrm{x}}-T_{\mathrm{g}}\right),{ }^{1,20)}$ enabling the formation of BGA rods with diameters of centimeter order by copper mold casting. An eutectic $\mathrm{Zr}_{50} \mathrm{Cu}_{40} \mathrm{Al}_{10}$ alloy exhibits the best GFA and its $d_{\mathrm{c}}$ reaches $16 \mathrm{~mm}^{21)}$ In addition, the $\mathrm{Zr}$-based BGAs also exhibit high fracture strength above $1800 \mathrm{MPa}$ with good toughness and excellent corrosion resistance in $1 \mathrm{~N} \mathrm{H}_{2} \mathrm{SO}_{4}$ solution. ${ }^{22,23)}$ If a new $\mathrm{Cu}$-rich $\mathrm{Zr}-\mathrm{Cu}-\mathrm{Al} \mathrm{BGA}$ with high GFA (e.g., $d_{\mathrm{c}}$ of over $1 \mathrm{~cm}$ via copper mold casting) is developed, it will be important for scientific studies as well as practical applications. In addition, the $\mathrm{Cu}$-rich BGAs can be expected to exhibit higher mechanical strength and higher thermal stability than those of the Zr-rich alloys. In this article, we report the finding of a new ternary $\mathrm{Cu}$-based $\mathrm{Cu}-\mathrm{Zr}$-Al BGA, what can be produced with the $d_{\mathrm{c}}$ up to $15 \mathrm{~mm}$, and exhibits large $\Delta T_{x}$ of $80 \mathrm{~K}$, high $T_{\mathrm{x}}$ of $794 \mathrm{~K}$ and high compressive fracture strength of over $1900 \mathrm{MPa}$. The possible mechanism for the high GFA of the Cu-based alloys is also discussed.

\section{Experimental Methods}

The master ingots were prepared by arc melting the mixtures of pure metals with purities of 99.9 mass $\%$ for $\mathrm{Zr}$, 99.99 mass\% for $\mathrm{Al}$ and $\mathrm{Cu}$ in an argon atmosphere. The alloy compositions present nominal atomic percentages. The injection casting method was applied to prepare glassy alloy rods of $2-5 \mathrm{~mm}$ in diameter and $40-50 \mathrm{~mm}$ in length by using a rectangular $\mathrm{Cu}$-mold of $40 \mathrm{~mm}$ in thickness, $50 \mathrm{~mm}$ in width and $120 \mathrm{~mm}$ in length. The tilt casting method ${ }^{24)}$ was used to prepare alloy rods of $6-16 \mathrm{~mm}$ in diameter and $40-$ $65 \mathrm{~mm}$ in length by using the rectangular Cu-molds of $60 \mathrm{~mm}$ in thickness, $70 \mathrm{~mm}$ in width and $100 \mathrm{~mm}$ in length. The surface of the cylindrical cavities was polished by $0.04 \mu \mathrm{m}$ $\mathrm{Al}_{2} \mathrm{O}_{3}$ powder to obtain a surface with roughness less than $\mathrm{Ra}$ 0.2 . Ribbon samples with a cross section of $0.02 \times 1.2 \mathrm{~mm}^{2}$ were prepared by melt spinning. The glassy structure of the 
cast alloy rods was identified by X-ray diffraction (XRD) and optical microscopy (OM). The etching for OM observation specimen was made in a $0.5 \%$ aqueous fluoride acid solution for $5 \mathrm{~s}$ at $298 \mathrm{~K}$. The rods were sectioned transversely, etched and observed by optical microscopy. The thermal stability associated with glass transition, supercooled liquid region and crystallization was examined by differential scanning calorimetry (DSC) at a heating rate of $0.67 \mathrm{~K} / \mathrm{s}$. The liquidus temperature and melting behavior was measured with a differential thermal analyzer (DTA) at a heating rate of $0.33 \mathrm{~K} / \mathrm{s}$. Mechanical properties under a compressive applied load were measured by using an Instron testing machine. The gauge dimensions for the mechanical test specimens were $\varphi 2 \times 4 \mathrm{~mm}^{2}$ and $2 \times 2 \times 4 \mathrm{~mm}^{3}$ for the compressive test and the strain rate was fixed as $5 \times 10^{-4} \mathrm{~s}^{-1}$. Young's modulus was measured by the strain gauge. Fracture morphology was examined by scanning electron microscopy (SEM).

\section{Results and Discussion}

We examined the effect of $\mathrm{Al}$ addition on the thermal stability and melting behavior of a binary $\mathrm{Cu}_{55} \mathrm{Zr}_{45}$ glassy alloy, what can form a bulk shape glassy sample with a $d_{\mathrm{c}}$ of $1.5 \mathrm{~mm}$ by a injection copper mold casting. ${ }^{16)}$ Figure 1 shows the DSC and DTA curves of melt-spun $\mathrm{Cu}_{55-x} \mathrm{Zr}_{45} \mathrm{Al}_{x}(x=$ $0-10)$ glassy alloys. The $T_{\mathrm{g}}, T_{\mathrm{x}}$, melting temperature $\left(T_{\mathrm{m}}\right)$ and $T_{1}$ are marked with arrows. All the samples exhibit a distinct endothermic heat event characteristic of the glass transition, followed by exothermic transformations from the undercooled liquid due to crystallization (see Fig. 1(a)). The $T_{\mathrm{g}}$ and $T_{\mathrm{x}}$ increase from 695 to 714 and 752 to $794 \mathrm{~K}$, respectively, with increasing $\mathrm{Al}$ content from $x=0$ to 8 , and then decrease with increasing $\mathrm{Al}$ content to $x=10$. The largest $\Delta T_{x}$ of $80 \mathrm{~K}$ is obtained for the alloy with $x=8$. From

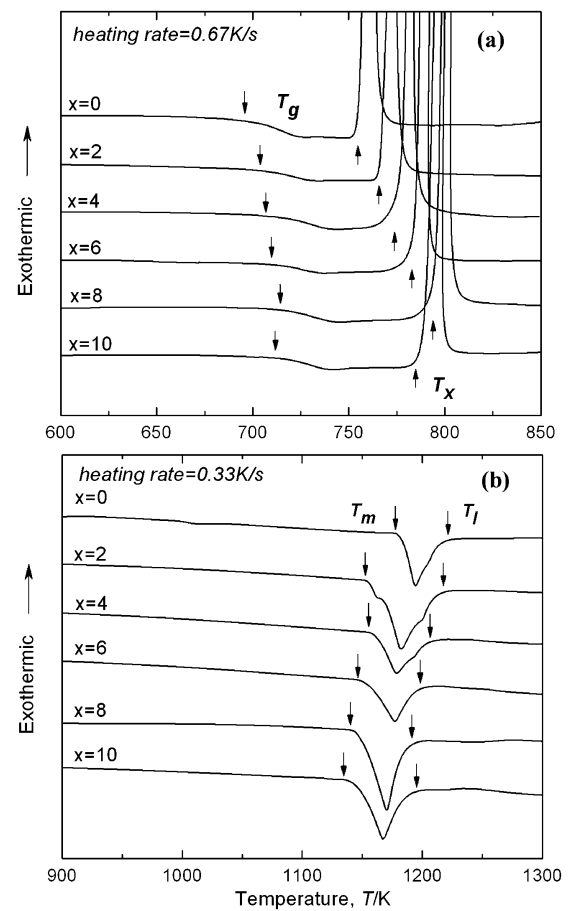

Fig. 1 DSC and DTA curves of $\mathrm{Cu}_{55-x} \mathrm{Zr}_{45} \mathrm{Al}_{x}(x=0-10$ at $\%)$ glassy alloys.

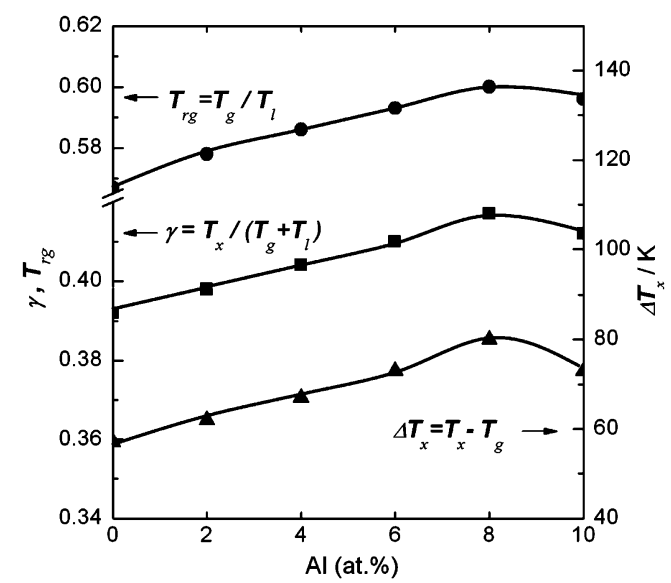

Fig. $2 \Delta T_{x}, T_{\mathrm{rg}}$ and $\gamma$ values of $\mathrm{Cu}_{55-x} \mathrm{Zr}_{45} \mathrm{Al}_{x}(x=0-10$ at $\%)$ glassy alloys as a function of $\mathrm{Al}$ concentration.

DTA curves (see Fig. 1(b)), only one endothermic peak is observed during melting of the alloy with $x=0$, because it is located near a deep binary eutectic. $\left.{ }^{25}\right)$ The $T_{1}$ decreases with increasing $\mathrm{Al}$ content from $x=0$ to 8 , and the $\mathrm{Cu}_{47} \mathrm{Zr}_{45} \mathrm{Al}_{8}$ alloy exhibits the lowest $T_{1}$ of $1190 \mathrm{~K}$, the narrowest temperature interval between $T_{\mathrm{m}}$ and $T_{1}$ and only a distinct endothermic peak. When the $\mathrm{Al}$ content is further increased to $x=10$, the $T_{1}$ rises. These results indicate that the $\mathrm{Cu}_{47} \mathrm{Zr}_{45} \mathrm{Al}_{8}$ alloy is located near a deep eutectic point in the ternary alloy system. Figure 2 shows the $\Delta T_{x}, T_{\mathrm{rg}}$ and $\gamma$ values as a function of $\mathrm{Al}$ concentration. It is seen that the large $\Delta T_{x}$ exceeding $65 \mathrm{~K}, T_{\mathrm{rg}}$ above 0.585 and $\gamma$ of over 0.40 are obtained in the $\mathrm{Al}$ content range of $4-10$ at $\%$. The $\mathrm{Cu}_{47} \mathrm{Zr}_{45} \mathrm{Al}_{8}$ alloy possesses simultaneously the largest $\Delta T_{x}$ of $80 \mathrm{~K}, T_{\mathrm{rg}}$ of 0.60 and $\gamma$ value of 0.417 , indicating the best glass former in the alloy series. ${ }^{1,18-20)}$

We examined the GFA of $\mathrm{Cu}_{47} \mathrm{Zr}_{45} \mathrm{Al}_{8}$ alloy by copper mold casting. Figure 3(a) shows the outer shape of the ascast $\mathrm{Cu}_{47} \mathrm{Zr}_{45} \mathrm{Al}_{8}$ rods with diameters ranging from 10 to $15 \mathrm{~mm}$. These alloy rods exhibit very smooth surface and shiny luster. Neither ruggedness nor concave is observed over the whole outer surface. Figure 3(b) shows the XRD patterns of the as-cast $\mathrm{Cu}_{47} \mathrm{Zr}_{45} \mathrm{Al}_{8}$ alloy rods with diameters from 10 to $15 \mathrm{~mm}$. It can be seen that the patterns consist of only broad peaks, and no diffraction peak corresponding to a crystalline phase is seen, indicating that a single glassy phase is formed. A further increase in the sample diameter to $16 \mathrm{~mm}$ results in the precipitation of crystalline phases. Thus, it is concluded that the critical sample diameter for formation of the glassy phase lies between 15 and $16 \mathrm{~mm}$ in the case of copper mold casting process. This equals to the best GFA for all Cu-based BGAs. Based on a simple relationship between the maximum thickness of the glassy alloys and the critical cooling rate $\left(R_{\mathrm{c}}\right)$ suggested by Lin et al., ${ }^{8)}$ the $R_{\mathrm{c}}$ of $\mathrm{Cu}_{47} \mathrm{Zr}_{45} \mathrm{Al}_{8}$ alloy for glass formation is estimated to be $18.9 \mathrm{~K} / \mathrm{s}$ or less.

The $\mathrm{Cu}_{55} \mathrm{Zr}_{45}$ alloy showed a narrower $\Delta T_{x}$ of $57 \mathrm{~K}$ and lower GFA $\left(d_{\mathrm{c}}=1.5 \mathrm{~mm}\right)$. The stabilization of supercooled liquid and GFA greatly increase by the addition of $\mathrm{Al}$ in the $\mathrm{Cu}_{55-x} \mathrm{Zr}_{45} \mathrm{Al}_{x}$ series, and the large $\Delta T_{x}$ of $80 \mathrm{~K}$ and the very high GFA with a $d_{\mathrm{c}}$ of $15 \mathrm{~mm}$ are obtained for the alloy with $x=8$. The empirical rules ${ }^{1,20)}$ drawn from experimental 
(a)
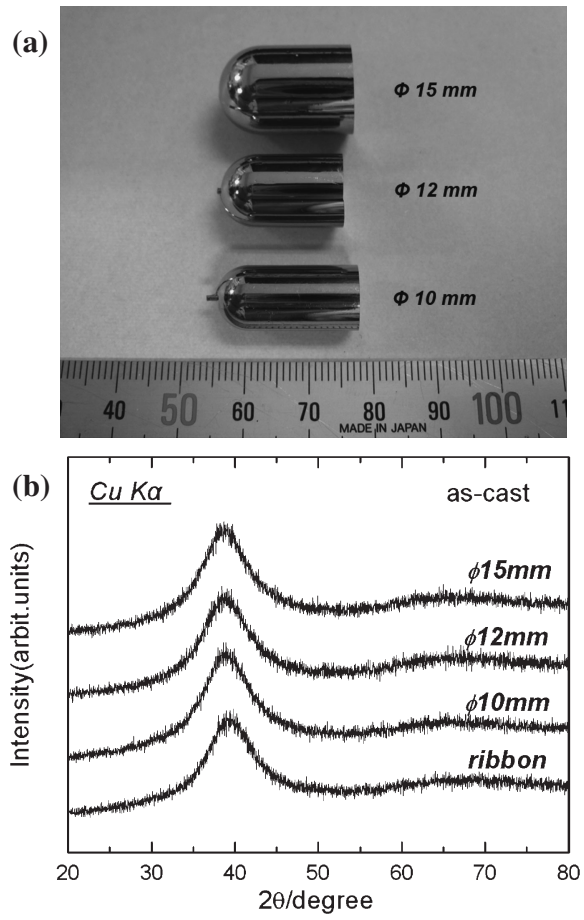

Fig. 3 (a) Outer shapes of as-cast $\mathrm{Cu}_{47} \mathrm{Zr}_{45} \mathrm{Al}_{8}$ rods with the diameters of 10-15 mm; (b) The cross-sectional XRD patterns of as-cast $\mathrm{Cu}_{47} \mathrm{Zr}_{45} \mathrm{Al}_{8}$ rods with the diameters of $10-15 \mathrm{~mm}$. The data of the ribbon sample is also shown for comparison.

results have shown that certain atomic-size mismatch and strong chemical affinities may enhance the stabilization of supercooled liquid and GFA of a multi-component system. In the present system, the atomic radii of the component atoms are $0.162 \mathrm{~nm}$ for $\mathrm{Zr}, 0.143 \mathrm{~nm}$ for $\mathrm{Al}$ and $0.128 \mathrm{~nm}$ for $\mathrm{Cu}$, respectively, ${ }^{26)}$ and hence $R_{\mathrm{Zr} / \mathrm{Cu}}=1.27, R_{\mathrm{Al} / \mathrm{Cu}}=1.12$ and $R_{\mathrm{Zr} / \mathrm{Al}}=1.13$. Therefore, the present combination of atomic sizes can produce an efficiently packed local structure, which is often associated with low energy and high viscosity of liquids. In addition, the addition of $\mathrm{Al}$ into the $\mathrm{Cu}-\mathrm{Zr}$ alloy (heats of mixing for $\mathrm{Cu}-\mathrm{Zr}$ pair is $-23 \mathrm{~kJ} / \mathrm{mol}$ ) causes the generation of new chemical affinities of $\mathrm{Al}-\mathrm{Zr}(-44 \mathrm{~kJ} / \mathrm{mol})$ and $\mathrm{Al}-\mathrm{Cu}(-1 \mathrm{~kJ} / \mathrm{mol})$ pairs, ${ }^{27)}$ which can improve the local packing efficiency and restrain long range diffusion of atoms. These factors lead to the high stability of the supercooled liquid and the high GFA.

It is noticed that $\mathrm{Cu}_{47} \mathrm{Zr}_{45} \mathrm{Al}_{8}$ alloy appears to be located near a deep eutectic composition. This also suggests that the GFA and stability of the glassy alloys are related to the eutectic composition. It is well known that alloys with compositions around the deep eutectic have high GFA and large $\Delta T_{x}$ in any given system. A deep eutectic means that the liquid has the highest stability against crystallization. Thus, the present high GFA is greatly favored thermodynamically. In addition, from the viewpoint of kinetics, the multi-component eutectic alloys consist of multiple ordered phases competing with each other, and crystallization of the liquid requires the simultaneous rearrangement of different species of atoms, which significantly suppresses the kinetics of crystallization process, leading to the enhancement of glass formation and the increase of $\Delta T_{x} .^{1,28)}$ Figure 4(a) shows a magnification picture of whole cross section of the
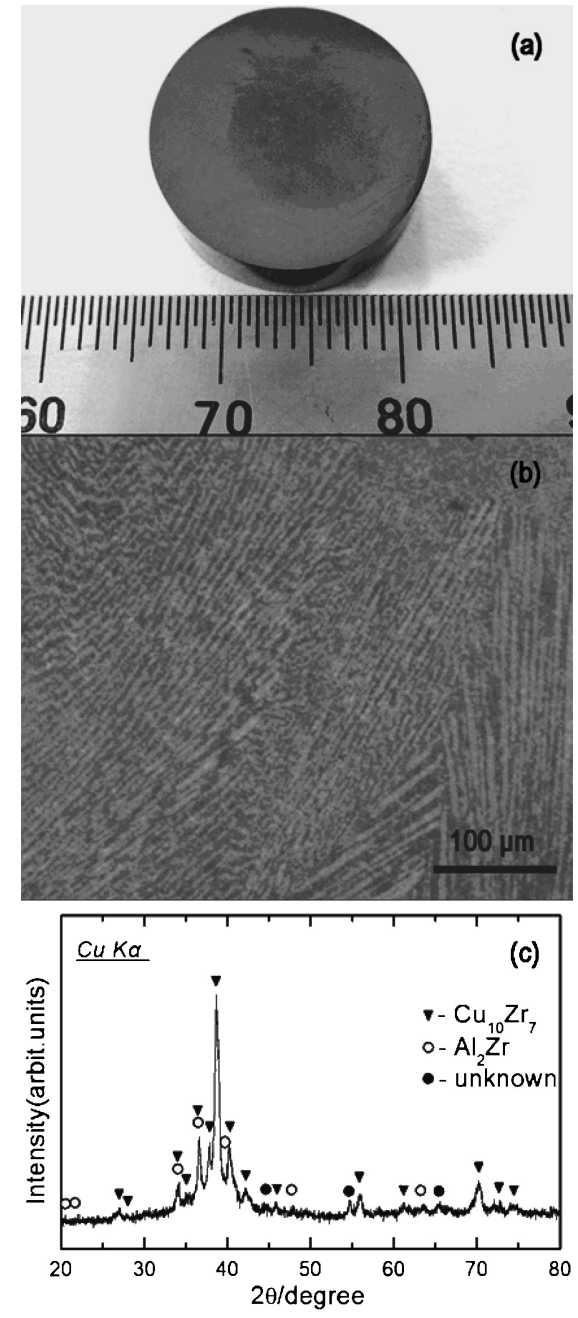

Fig. 4 (a) The optical micrographs of cross section of the as-cast $\mathrm{Cu}_{47} \mathrm{Zr}_{45} \mathrm{Al}_{8}$ alloy rod with a diameter of $16 \mathrm{~mm}$; (b) The cross-sectional structure taken from center of the as-cast alloy rod; (c) The cross-sectional XRD pattern taken from center of the as-cast alloy rod.

as-cast $\mathrm{Cu}_{47} \mathrm{Zr}_{45} \mathrm{Al}_{8}$ alloy rod with a diameter of $16 \mathrm{~mm}$. It can be seen that there is a crystalline region (dark contrast) in the center of the cross section. The uniform and fine eutectic structure consisting of $\mathrm{Cu}_{10} \mathrm{Zr}_{7}, \mathrm{Al}_{2} \mathrm{Zr}$ and other unknown phases (see Fig. 4(b) and (c)) is observed in the crystalline region. These results also confirm that the solidification of the supercooled liquid occurs through an eutectic reaction.

Figure 5 shows compressive stress-strain curves of the cast $\mathrm{Cu}_{47} \mathrm{Zr}_{45} \mathrm{Al}_{8}$ alloy rod with the diameters of 2 and $12 \mathrm{~mm}$. The test specimens were taken from the central and outer surface regions in the transverse cross section at the fixed site which is about $10 \mathrm{~mm}$ away from the bottom surface of the alloy rod with a diameter $12 \mathrm{~mm}$ (see Ref. 29)). The glassy rod sample with a diameter of $2 \mathrm{~mm}$ exhibits high fracture strength $\left(\sigma_{\mathrm{c}, \mathrm{f}}\right)$ of $1923 \mathrm{MPa}$, and the Young's modulus $(E)$ is estimated to be $108 \mathrm{GPa}$. Although the alloy does not show a distinct plastic strain, it is confirmed that the samples fracture along the maximum shear stress plane which is declined by about 45 degrees to the direction of applied load and the fracture surface consists of mainly a well developed vein pattern, suggesting that the fracture behavior is similar to 


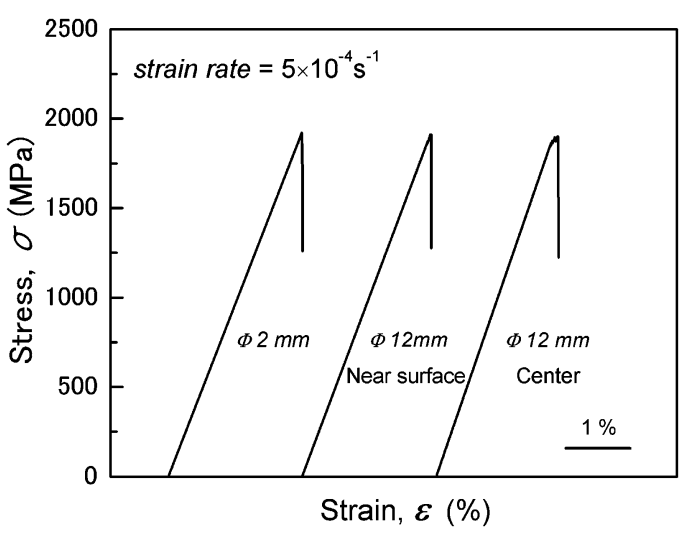

Fig. 5 Compressive stress-strain curves of $\mathrm{Cu}_{47} \mathrm{Zr}_{45} \mathrm{Al}_{8}$ glassy rods with a diameter of 2 and $12 \mathrm{~mm}$.

other BGAs with some plastic strain before fracture. ${ }^{9,11)}$ For the glassy rod sample with a diameter of $12 \mathrm{~mm}$, the $\sigma_{\mathrm{c}, \mathrm{f}}$ and $E$ values are $1900 \mathrm{MPa}$ and $101 \mathrm{GPa}$ respectively, at the central region, and $1915 \mathrm{MPa}$ and $103 \mathrm{GPa}$, respectively, at the outer surface region. Thus, the mechanical properties appear to be independent of the sample size and the sample site in the transverse cross section.

\section{Summary}

With the aim of developing new Cu-based BGAs with a critical size of centimeters in a simple system, the thermal stability, melting behaviors and GFA of $\mathrm{Cu}_{55-x} \mathrm{Zr}_{45} \mathrm{Al}_{x}$ $(x=0-10)$ alloys were investigated. The large $\Delta T_{x}$ exceeding $65 \mathrm{~K}, T_{\text {rg }}$ above 0.585 and $\gamma$ of over 0.40 are obtained in the $\mathrm{Al}$ content range of $4-10$ at\%. The eutectic $\mathrm{Cu}_{47} \mathrm{Zr}_{45} \mathrm{Al}_{8}$ alloy simultaneously exhibits the largest $\Delta T_{x}$ of $80 \mathrm{~K}, T_{\mathrm{rg}}$ of 0.60 and $\gamma$ of 0.417 , leading to formation of full glassy samples with diameters up to $15 \mathrm{~mm}$. This is comparable to the best GFA for all $\mathrm{Cu}$-based BGAs. The $\mathrm{Cu}$-based BGA exhibits high compressive fracture strength of over $1900 \mathrm{MPa}$ and the high Young's modulus above $100 \mathrm{GPa}$. The combination of high GFA, high stabilization of supercooled liquid and good mechanical properties for a simple $\mathrm{Cu}$-based alloy composition with low materials cost is providing the base alloy for further exploring the BGAs' formers with higher GFA, and giving them excellent promise for both scientific and engineering applications.

\section{Acknowledgement}

This work was supported by Grant-In-Aid for Scientific Research (C) (No. 19560689), and Research and Development Project on Advanced Metallic Glasses, Inorganic Materials and Joining Technology from the Ministry of Education, Culture, Sports, Science and Technology, Japan.

\section{REFERENCES}

1) A. Inoue: Acta Mater. 48 (2000) 279-306.

2) W. L. Johnson: MRS Bull. 24 (1999) 42-56.

3) A. Inoue, T. Zhang and T. Masumoto: Mater. Trans. 36 (1995) 391398.

4) T. Zhang and A. Inoue: Mater. Trans. 39 (1998) 1001-1106.

5) A. Inoue, W. Zhang and T. Zhang: Mater. Trans. 43 (2002) 1952-1955.

6) W. Zhang and A. Inoue: Scr. Mater. 48 (2003) 641-645.

7) D. Xu, G. Duan and W. L. Johnson: Acta Mater. 52 (2004) 3493-3496.

8) X. H. Lin and W. L. Johnson: J. Appl. Phys. 78 (1995) 5619-6514.

9) A. Inoue, W. Zhang, T. Zhang and K. Kurosaka: Acta Mater. 49 (2001) 2645-2652.

10) A. Inoue and W. Zhang: Mater. Trans. 43 (2002) 2921-2925.

11) W. Zhang and A. Inoue: J. Mater. Res. 21 (2006) 234-241.

12) A. Inoue and T. Zhang: Mater. Trans. JIM 37 (1996) 185-187.

13) W. L. Johnson: Mater. Sci. Forum 225-227 (1996) 35.

14) W. Zhang, Q. Zhang and A. Inoue: J. Mater. Res. 23 (2008) 1452-1456.

15) A. Inoue and W. Zhang: Mater. Trans. 45 (2004) 584-587.

16) D. Wang, Y. Li, B. B. Sun, M. L. Sui, K. Lu and E. Ma: Appl. Phys. Lett. 84 (2004) 4029-4031.

17) M. B. Tang, D. Q. Zhao, M. X. Pan and W. H. Wang: Chinese Phys. Lett. 21 (2004) 901-903.

18) D. Turnbull: Contempt Phys. 10 (1969) 473.

19) Z. P. Lu and C. T. Liu: Acta. Mater. 50 (2002) 3501-3512.

20) A. Inoue: Mater. Trans. JIM 36 (1995) 866-875.

21) Y. Yokoyama, T. Yamasaki, P. K. Liaw, R. A. Buchanan and A. Inoue: Mater. Sci. Eng. A 449-451 (2007) 621-626.

22) W. Zhang, Q. S. Zhang, C. Qin and A. Inoue: Mater. Sci. Eng. B 148 (2008) 92-96.

23) T. Wada, F. X. Qin, X. M. Wang, M. Yoshimura, A. Inoue, N. Sugiyama, R. Ito and N. Matsushita: J. Mater. Res. 24 (2009) 29412948.

24) Y. Yokoyama, K. Fukaura and A. Inoue: Intermetallics 10 (2002) 1113-1124.

25) P. Nash and C. S. Jayanth: Bull. Alloy Phase Diagrams 5 (1984) 144148.

26) Metals Databook: Japan Inst. Metals, (Maruzen, Tokyo, 1983) p. 8.

27) F. R. de Boer, R. Boom, W. C. M. Mattens, A. R. Miedema and A. K. Niessen: Cohesion in Metals, (North-Holland, Amsterdam, 1988).

28) D. H. Xu, G. Duan and W. L. Johnson: Phys. Rew. Lett. 92 (2004) 245504-1-245504-4.

29) Q. S. Zhang, W. Zhang, X. Wang, Y. Yokoyama, K. Yubuta and A. Inoue: Mater. Trans. 49 (2008) 2141-2146. 